\title{
Ethnic differences in blood pressure monitoring and control in south east London
}

\author{
Peter Schofield, Omer Saka and Mark Ashworth
}

\begin{abstract}
Background

High blood pressure is the single most important risk factor worldwide for the development of cardiovascular disease, and has been shown to affect some ethnic minority groups disproportionately.

Aim

To explore ethnic inequalities in blood pressure monitoring and control.

Method

Data from Lambeth DataNet was used, based on case records from GP practices in one inner-city London borough. Blood pressure monitoring and control was compared using Quality and Outcomes Framework (QOF) targets for patients with: diabetes, coronary heart disease, stroke, hypertension, and chronic kidney disease. The study controlled for age, sex, social deprivation, and clustering within GP practices.

Results

A total of 16613 patients met the study criteria, with 5962 categorised as black/black British. Blood pressure monitoring was similar across ethnic groups and as good, if not better, for black patients compared to white. However, marked ethnic inequalities in blood pressure control were found, with black patients significantly less likely to achieve QOF targets than their white counterparts (odds ratio [OR] 0.73; 95\% confidence interval $[\mathrm{Cl}]=0.64$ to 0.82 ). Further inequalities were revealed in blood pressure control within disease groups and ethnic subgroups. In particular, blood pressure control was poor in African patients with diabetes (OR $0.63 ; 95 \% \mathrm{Cl}=0.50$ to 0.79 ) and Caribbean patients with coronary heart disease (OR $0.53 ; 95 \% \mathrm{Cl}=0.37$ to 0.77 ) when compared with white patients.
\end{abstract}

Discussion

While black patients with chronic conditions are equally likely to have their blood pressure monitored, their blood pressure control is consistently poorer than that of their white counterparts. This may have important implications for cardiovascular risk management in black patients.

Keywords

ethnicity/race; inequalities; health care; hypertension.

\section{INTRODUCTION}

The burden of cardiovascular disease is unevenly distributed within the general population. For example, the incidence of coronary heart disease (CHD) has been shown to be consistently higher among South Asians, while the incidence of stroke is more common among African-Caribbean individuals compared to the white population., ${ }^{1,2}$ Furthermore, socioeconomically deprived populations experience higher rates of both heart disease and stroke.,34

Differences in the incidence of cardiovascular disease are largely related to the social distribution of cardiovascular disease risk factors, of which hypertension is the single most important. ${ }^{5}$ UK studies have shown an increased prevalence of hypertension (up to three or four times greater) among black people compared to the rest of the population. ${ }^{6-9}$ With regard to treatment, there is some evidence that detection rates are better for black compared to white patients. ${ }^{10,11}$ However, it is claimed that black patients on drug treatment for hypertension have overall poorer blood pressure control. ${ }^{10}$ While in the US this has been a consistent finding, this has not always been replicated in UK studies. ${ }^{11-13}$ This may be because these are based on either very small and geographically highly specific populations, ${ }^{10}$ or

P Schofield, PhD, MSc, BSc, senior research fellow; O Saka, $M D, M S c$, health economist; $M$ Ashworth, DM, FRCGP, MRCP, clinical senior lecturer, Department of Primary Care and Public Health Sciences, Kings College London, London.

Address for correspondence

Dr Peter Schofield, King's College London, Department of Primary Care and Public Health Sciences, 7th Floor, Capital House, 42 Weston Street, London, SE1 3QD.

E-mail: peter.1.schofield@kcl.ac.uk

Submitted: 25 May 2010; Editor's response: 15 June 2010; final acceptance: 13 July 2010.

(OBritish Journal of General Practice

This is the full-length article (published online $28 \mathrm{Mar} 2011$ ) of an abridged version published in print. Cite this article as: Br J Gen Pract 2011; DOI: 10.3399/bjgp11X567126. 
conversely, that they rely on national survey data which, despite oversampling, leads to a relatively small and diffuse black and ethnic minority (BEM) sample. ${ }^{12,13}$

Looking at inequalities in terms of deprivation, there is evidence to show that the Quality and Outcomes Framework (QOF) has led to an incremental reduction in the inequalities gap. ${ }^{14}$ This is particularly so for blood pressure treatment, where a recent study has shown that differences between practice outcomes in the most and least deprived areas have narrowed to the point of convergence. ${ }^{15}$ The latter study also found the proportion of black residents in a practice area had the greatest confounding effect. Only one study has, so far, looked specifically at ethnic differences in blood pressure treatment since the QOF was introduced. ${ }^{16}$ This south west London study found that black patients with hypertension were significantly less likely to achieve QOF blood pressure targets compared to their white counterparts (odds ratio $[\mathrm{OR}]=0.86,95 \%$ confidence interval $[\mathrm{Cl}]=0.74$ to 0.99). It is possible that, since then, there has been a reduction in ethnic inequalities in the same way that deprivation inequalities have reduced. This study set out to examine this by looking at ethnic inequalities in blood pressure monitoring and control, using recently collected data from a large sample of practices in Lambeth, south east London.

\section{METHOD}

The Lambeth DataNet was used to compare QOF blood pressure outcomes for patients with the following cardiovascular-related diseases: diabetes, CHD, stroke, hypertension, and chronic kidney disease (CKD).

\section{Study design}

The dataset comprises electronic patient records from practices in Lambeth. Lambeth has the second highest proportion of 'black' or 'black British' residents in the UK, at $25.8 \%$ (neighbouring Southwark has the highest proportion at $25.9 \%){ }^{17}$

The database was originally set up to improve both the level and quality of ethnicity coding in GP data, in order to facilitate ethnic monitoring of health inequalities. ${ }^{18}$ Several strategies were used to improve both the level and quality of ethnicity coding. ${ }^{19}$

\section{Study sample}

To facilitate data extraction, the study sample was restricted to only those practices using the EMIS (Egton Medical Information Systems) LV computer system, comprising just over half (27/53) the GP practices in Lambeth. The study sample covered all patients (192 432) from these practices, and data

\section{How this fits in}

High blood pressure has been shown to be more prevalent among black and ethnic minority groups; however, studies looking at drug treatment for hypertension have shown inconsistent results when comparing blood pressure monitoring and control. This study looked at a large sample of primary care patients in Lambeth and found that African-Caribbean patients with hypertension had more frequent blood pressure recording compared to whiteBritish patients. Nevertheless, blood pressure control was significantly worse in African-Caribbean patients.

were extracted from local practice computer systems in March 2009, using MIQUEST software.

\section{Outcome measures}

Outcomes for blood pressure monitoring and control were primarily based on QOF targets for each chronic disease. Blood pressure monitoring was coded as positive for those with diabetes, CHD, stroke, and CKD, if there was a record of blood pressure measured in the past 15 months and, for hypertension, the past 9 months. Blood pressure control was coded as positive for those with hypertension, CHD, or stroke if their last recorded blood pressure was $150 / 90 \mathrm{mmHg}$ or less. For patients with diabetes, the target was $145 / 85 \mathrm{mmHg}$ or less, and for those with CKD $140 / 85 \mathrm{mmHg}$ or less. The most recent systolic, diastolic, and mean arterial pressures were also examined; the latter was calculated as: [(systolic blood pressure $)+(2 \times$ diastolic blood pressure)]/3. ${ }^{20}$

\section{Predictors}

Patient ethnicity codes were mapped on to UK census ethnic categories. ${ }^{17}$ Initially outcomes were compared for white (white British), black (black or black British) and Asian (Asian or Asian British) patients. It has been argued that more detailed ethnic definitions are justified when exploring differences in blood pressure treatment. ${ }^{9}$ Therefore, a subgroup analysis was conducted comparing patients in the more detailed 'other white' (excluding those coded English, Scottish, Welsh, or Northern Irish), black African and black Caribbean census categories. For brevity, the terms African and Caribbean will be used when referring to the latter ethnic groups, and white when referring to the white British group.

Relative social deprivation was assessed at patient level by mapping patient postcodes to lower super output areas and assigning the Index of Multiple Deprivation (IMD 07) score $^{21}$ for each patient's immediate neighbourhood. Age, sex, and number of comorbidities (of the five specified chronic diseases) were also adjusted for. 


\section{Statistical analysis}

The effect of ethnicity on whether patients met QOF blood pressure targets was assessed using logistic regression in Stata (version 10). Recent blood pressure levels were also analysed as a continuous outcome using multiple regression. For each analysis, the standard errors were adjusted to account for the effect of clustering at practice level, using the Huber/White sandwich estimating procedure.

\section{RESULTS}

Ethnicity data were obtained for 129700 (67.3\%) patients and, of these, 19800 had a record of at least one of the five specified chronic disease groups. The main ethnic groups comprised 6543 (33\%) classified as white British; 2999 (15.1\%) Caribbean; and 2313 (11.7\%) African (Table 1). Patients with and without ethnicity data were compared and no sex difference was found, although there was a small age effect, with those whose ethnicity was uncoded being slightly younger (mean age 62.2 years) than those with ethnicity data (mean age 63.3 years), and this difference was statistically significant $(P<0.001)$.

Table 2 shows how each chronic disease was distributed among the five main ethnic groups in the study sample. While ethnic differences here are broadly in line with what would be expected, it is notable that Caribbean, and not African, patients were over-represented in the hypertension group. However, when the results were adjusted for age and sex, this difference disappeared.

To ensure that the practice sample was not subject to selection bias, it was compared with the remaining
Lambeth practices on the following key variables: list size; area deprivation and ethnic composition (based on practice postcode); and average age of registered patients. No significant differences were found between the two practice groups.

The analysis of blood pressure monitoring showed little evidence of any ethnic inequality (Table 3 ). Caribbean patients were more likely to have their blood pressure monitored recently in the diabetes (OR 1.94; $95 \% \mathrm{Cl}=1.12$ to 3.35 ) and hypertension groups (OR 1.32; 95\% Cl = 1.05 to 1.66). Also, stroke patients in the other white group stood out as being significantly more likely to have their blood pressure monitored (OR $3.76 ; 95 \% \mathrm{Cl}=1.00$ to 14.05). When the results for all chronic diseases patients were pooled, the Caribbean group were, overall, more likely to have their blood pressure monitored (OR $1.32 ; 95 \% \mathrm{Cl}=1.07$ to 1.64$)$, as were patients in the Asian group (OR 1.34; 95\% Cl = 1.08 to 1.67 ).

In contrast, the successful achievement of QOF blood pressure control targets was less likely, overall, for black patients compared to white patients (OR $0.73 ; 95 \% \mathrm{Cl}=0.64$ to 0.82 ) (Table 4) and this applied to all but one (stroke) of the chronic disease groups. For example, black patients with $\mathrm{CHD}$ were significantly less likely to reach QOF targets for blood pressure control (OR 0.56; $95 \% \mathrm{Cl}=0.39$ to 0.81 ) compared to white patients. A similar magnitude of effect was found for stroke patients, although this did not reach statistical significance, possibly due to the relatively small number of stroke patients in the study sample (Table 2). Not only was blood pressure control shown to be poorer in black patients, but their prevalence of cardiovascular disease-related

Table 1. Characteristics of patients with chronic conditions: by ethnic group.

\begin{tabular}{lcccccc} 
& White British & Other white, & Asian, & Caribbean, & African, & Total, \\
$n=6543$ & $n=150$ & $n=1092$ & $n=2999$ & $n=2313$ & $n=14297$ \\
\hline Age, years & 67.3 & 61.7 & 61.3 & 63.3 & 54.9 & 63.5 \\
\hline Sex, \% male & 49.1 & 48.4 & 52.7 & 40.2 & 46.3 & 47.0 \\
\hline Comorbidities, $n$ & 1.5 & 1.4 & 1.6 & 1.5 & 1.3 & 1.5 \\
\hline Area social deprivation score (IMD 07) & 33.7 & 35.0 & 32.5 & 36.8 & 38.7 & 35.2 \\
\hline
\end{tabular}

Table 2. Chronic disease crude prevalence: by ethnic group.

\begin{tabular}{|c|c|c|c|c|c|c|}
\hline & $\begin{array}{c}\text { White British, } \\
n=50396\end{array}$ & $\begin{array}{c}\text { Other white, } \\
n=21874\end{array}$ & $\begin{array}{c}\text { Asian, } \\
n=6972\end{array}$ & $\begin{array}{l}\text { Caribbean, } \\
n=12193\end{array}$ & $\begin{array}{c}\text { African, } \\
n=15140\end{array}$ & $\begin{array}{c}\text { Total, } \\
n=106575\end{array}$ \\
\hline Diabetes, \% (n) & $3.0(1508)$ & $2.1(459)$ & $8.0(556)$ & $9.9(1208)$ & $4.9(737)$ & $4.2(4468)$ \\
\hline Hypertension, \% (n) & $10.4(5217)$ & $4.7(1025)$ & $11.5(802)$ & $21.6(2630)$ & $12.8(1939)$ & $10.9(11613)$ \\
\hline Coronary heart disease, \% (n) & ר) $2.0(1030)$ & $0.8(175)$ & $2.9(202)$ & $1.5(186)$ & $0.4(67)$ & $1.6(1660)$ \\
\hline Stroke, \% $(n)$ & $3.0(643)$ & $1.8(104)$ & $2.8(73)$ & $3.7(231)$ & $1.8(99)$ & $2.8(1150)$ \\
\hline Chronic kidney disease, \% (n) & ר) $2.2(1097)$ & $0.6(141)$ & $1.9(131)$ & $3.2(386)$ & $1.0(152)$ & $1.8(1907)$ \\
\hline Any of the above, \% (n) & $13.0(6543)$ & $6.2(1350)$ & 15.7 (1092) & 24.6 (2999) & $15.3(2313)$ & 13.4 (14 297) \\
\hline
\end{tabular}


Table 3. Ethnic differences (adjusted odds ratio a and percentage achieving QOF target) in blood pressure monitoring for patients with chronic conditions.

\begin{tabular}{|c|c|c|c|c|c|c|c|}
\hline & $\begin{array}{l}\text { White } \\
\text { British }\end{array}$ & $\%$ & $\begin{array}{l}\text { Other white, } \\
\text { OR (95\% Cl) \% }\end{array}$ & $\begin{array}{l}\text { Asian, } \\
\text { OR }(95 \% \text { Cl) \% }\end{array}$ & $\begin{array}{l}\text { Caribbean, } \\
\text { OR }(95 \% \text { Cl) \% }\end{array}$ & $\begin{array}{c}\text { African, } \\
\text { OR }(95 \% \mathrm{Cl}) \%\end{array}$ & $\begin{array}{c}\text { Black }^{\mathrm{b}} \\
\text { (combined), } \\
\text { OR }(95 \% \mathrm{Cl}) \%\end{array}$ \\
\hline Diabetes & - & 94.6 & $\begin{array}{c}0.76 \quad 93.1 \\
(0.52 \text { to } 1.11)\end{array}$ & $\begin{array}{c}0.85 \quad 93.7 \\
(0.48 \text { to } 1.51)\end{array}$ & $\begin{array}{c}1.94 \quad 97.1 \\
(1.12 \text { to } 3.35)^{\circ}\end{array}$ & $\begin{array}{c}0.96 \quad 94.4 \\
(0.61 \text { to } 1.51)\end{array}$ & $\begin{array}{c}1.2795 .8 \\
(0.88 \text { to } 1.83)\end{array}$ \\
\hline Hypertension & - & 84.2 & $\begin{array}{c}0.89 \quad 82.7 \\
(0.75 \text { to } 1.06)\end{array}$ & $\begin{array}{c}1.33 \quad 87.7 \\
(0.95 \text { to } 1.87)\end{array}$ & $\begin{array}{c}1.32 \quad 87.6 \\
(1.05 \text { to } 1.66)^{\circ}\end{array}$ & $\begin{array}{c}1.12 \quad 85.7 \\
(0.86 \text { to } 1.46)\end{array}$ & $\begin{array}{c}1.22 \quad 86.7 \\
(0.98 \text { to } 1.52)\end{array}$ \\
\hline Stroke & - & 89.6 & $\begin{array}{c}3.76 \quad 97.0 \\
(1.00 \text { to } 14.05)^{\mathrm{a}}\end{array}$ & $\begin{array}{c}2.30 \quad 95.2 \\
(0.47 \text { to } 11.19)\end{array}$ & $\begin{array}{c}0.95 \quad 89.1 \\
(0.41 \text { to } 2.21)\end{array}$ & $\begin{array}{c}0.7186 .0 \\
(0.32 \text { to } 1.57)\end{array}$ & $\begin{array}{c}0.8588 .2 \\
(0.44 \text { to } 1.65)\end{array}$ \\
\hline Chronic kidney disease & - & 92.5 & $\begin{array}{c}0.94 \quad 92.1 \\
(0.40 \text { to } 2.23)\end{array}$ & $\begin{array}{c}1.15 \quad 93.4 \\
(0.36 \text { to } 3.64)\end{array}$ & $\begin{array}{c}1.68 \quad 95.4 \\
(0.41 \text { to } 6.83)\end{array}$ & $\begin{array}{c}0.97 \quad 92.3 \\
(0.38 \text { to } 2.46)\end{array}$ & $\begin{array}{c}1.20 \quad 93.8 \\
(0.55 \text { to } 2.62)\end{array}$ \\
\hline All diseases & - & 85.6 & $\begin{array}{c}0.94 \quad 84.8 \\
(0.80 \text { to } 1.10)\end{array}$ & $\begin{array}{c}1.34 \quad 88.9 \\
(1.08 \text { to } 1.67)^{d}\end{array}$ & $\begin{array}{c}1.32 \quad 88.7 \\
(1.07 \text { to } 1.64)^{c}\end{array}$ & $\begin{array}{c}1.06 \quad 86.3 \\
(0.85 \text { to } 1.33)\end{array}$ & $\begin{array}{c}1.18{ }^{87.5} \\
(0.97 \text { to } 1.43)\end{array}$ \\
\hline
\end{tabular}

$\mathrm{OR}=$ odds ratio. ${ }^{\mathrm{a}}$ Comparing the odds of patients from a given ethnic group having a positive outcome compared to white British patients. Coefficients are adjusted for age, sex, number of comorbidities, and social deprivation. An odds ratio greater than one indicates improved monitoring and less than one indicates poorer monitoring. ${ }^{b}$ Caribbean and African categories combined. ${ }^{c} P<0.05 ;{ }^{d} P<0.01$.

Table 4. Ethnic differences (adjusted odds ratio and percentage achieving QOF target) in blood pressure control for patients with chronic conditions.

\begin{tabular}{|c|c|c|c|c|c|c|c|}
\hline & $\begin{array}{l}\text { White } \\
\text { British }\end{array}$ & $\%$ & $\begin{array}{l}\text { Other white, } \\
\text { OR }(95 \% \text { Cl) \% }\end{array}$ & $\begin{array}{c}\text { Asian, } \\
\text { OR }(95 \% \text { Cl) \% }\end{array}$ & $\begin{array}{l}\text { Caribbean, } \\
\text { OR }(95 \% \mathrm{Cl}) \%\end{array}$ & $\begin{array}{c}\text { African, } \\
\text { OR }(95 \% \mathrm{Cl}) \%\end{array}$ & $\begin{array}{c}\text { Black }^{\mathrm{b}} \\
\text { (combined), } \\
\text { OR }(95 \% \mathrm{Cl})\end{array}$ \\
\hline \multirow[t]{2}{*}{ Diabetes } & - & 79.4 & 1.12 & 79.2 & 77.3 & 0.63 & 0.78 \\
\hline & & & (0.84 to 1.49$)$ & (0.77 to 1.27$)$ & (0.72 to 1.08$)$ & $(0.50 \text { to } 0.79)^{\mathrm{e}}$ & $(0.65 \text { to } 0.93)^{d}$ \\
\hline \multirow[t]{2}{*}{ Hypertension } & - & 80.6 & 80.2 & 1.27 & 77.8 & 75.7 & 0.80 \\
\hline & & & (0.80 to 1.18$)$ & (0.89 to 1.80$)$ & $(0.72 \text { to } 0.98)^{c}$ & $(0.63 \text { to } 0.89)^{e}$ & $(0.70 \text { to } 0.91)^{\mathrm{e}}$ \\
\hline \multirow[t]{2}{*}{ Coronary heart disease } & - & 90.2 & 1.13 & $0.79 \quad 87.9$ & 0.53 & 0.64 & 0.56 \\
\hline & & & (0.73 to 1.73$)$ & (0.49 to 1.29$)$ & $(0.37 \text { to } 0.77)^{\mathrm{e}}$ & (0.28 to 1.46$)$ & $(0.39 \text { to } 0.81)^{d}$ \\
\hline \multirow[t]{2}{*}{ Stroke } & - & 87.7 & 85.2 & 93.4 & 83.4 & 81.6 & 0.70 \\
\hline & & & $(0.44$ to 1.49$)$ & (0.86 to 4.60$)$ & $(0.44$ to 1.12$)$ & $(0.34$ to 1.16$)$ & $(0.45$ to 1.07$)$ \\
\hline \multirow[t]{2}{*}{ Chronic kidney disease } & - & 71.9 & 0.81 & 1.53 & 66.4 & 59.3 & 0.72 \\
\hline & & & (0.58 to 1.14$)$ & (0.90 to 2.61$)$ & $(0.57$ to 1.04$)$ & $(0.36 \text { to } 0.90)^{c}$ & $(0.55 \text { to } 0.95)^{c}$ \\
\hline \multirow[t]{2}{*}{ All diseases } & - & 79.2 & 0.99 & 80.8 & 74.7 & 71.6 & 0.73 \\
\hline & & & (0.83 to 1.19$)$ & (0.83 to 1.47$)$ & $(0.66 \text { to } 0.91)^{d}$ & $(0.57 \text { to } 0.76)^{\mathrm{e}}$ & $(0.64 \text { to } 0.82)^{\mathrm{e}}$ \\
\hline
\end{tabular}

$\mathrm{O} R=$ odds ratio. a Comparing the odds of patients from a given ethnic group having a positive outcome compared to white British patients. Coefficients are adjusted for age, sex, number of comorbidities, and social deprivation. An odds ratio greater than one indicates improved monitoring and less than one indicates poorer monitoring. ${ }^{b}$ Caribbean and African categories combined. ${ }^{c} P<0.05 .{ }^{d} P<0.01 .{ }^{e} P<0.001$.

Table 5. Ethnic differences (adjusted mean difference ${ }^{a}$ and mean blood pressure levels) in blood pressure values for all chronic patients.

\begin{tabular}{|c|c|c|c|c|c|c|c|}
\hline & $\begin{array}{l}\text { White } \\
\text { British }\end{array}$ & $\mathrm{mmHg}$ & $\begin{array}{l}\text { Other white, } \\
B(95 \% \mathrm{Cl}) \mathrm{mmHg}\end{array}$ & $\begin{array}{l}\text { Asian, } \\
B(95 \% \mathrm{Cl}) \mathrm{mmHg}\end{array}$ & $\begin{array}{l}\text { Caribbean, } \\
B(95 \% \mathrm{Cl}) \mathrm{mmHg}\end{array}$ & $\begin{array}{l}\text { African, } \\
\text { B (95\% Cl) } \mathrm{mmHg}\end{array}$ & $\begin{array}{l}\text { Black }^{\mathrm{b}} \\
\text { (combined), } \\
\text { B }(95 \% \mathrm{Cl}) \mathrm{mmHg}\end{array}$ \\
\hline $\begin{array}{l}\text { Systolic blood } \\
\text { pressure }\end{array}$ & - & 135.2 & $\begin{array}{l}-0.06 \quad 135.1 \\
(-1.56 \text { to } 1.45)\end{array}$ & $\begin{array}{c}-1.42 \quad 133.8 \\
(-2.70 \text { to }-0.14)^{\circ}\end{array}$ & $\begin{array}{c}2.59{ }^{137.8} \\
(1.57 \text { to } 3.61)^{d}\end{array}$ & $\begin{array}{c}3.67138 .8 \\
(2.53 \text { to } 4.80)^{d}\end{array}$ & $\begin{array}{c}2.96 \quad 138.2 \\
(2.17 \text { to } 3.75)^{d}\end{array}$ \\
\hline $\begin{array}{l}\text { Diastolic blood } \\
\text { pressure }\end{array}$ & - & 78.4 & $\begin{array}{c}-0.09{ }^{7} 78.3 \\
(-0.77 \text { to } 0.59)\end{array}$ & $\begin{array}{c}-0.34{ }^{78.0} \\
(-1.27 \text { to } 0.60)\end{array}$ & $\begin{array}{c}1.89{ }^{80.3} \\
(1.25 \text { to } 2.53)^{d}\end{array}$ & $\begin{array}{c}2.0680 .4 \\
(1.43 \text { to } 2.69)^{d}\end{array}$ & $\begin{array}{c}1.94{ }^{80.3} \\
(1.41 \text { to } 2.46)^{d}\end{array}$ \\
\hline $\begin{array}{l}\text { Mean arterial blood } \\
\text { pressure }\end{array}$ & - & 97.3 & $\begin{array}{c}-0.07 \quad 97.2 \\
(-0.93 \text { to } 0.80)\end{array}$ & $\begin{array}{c}-0.68 \quad 96.6 \\
(-1.34 \text { to }-0.03)^{\circ}\end{array}$ & $\begin{array}{c}2.16 \quad 99.5 \\
(1.42 \text { to } 2.90)^{d}\end{array}$ & $\begin{array}{c}2.6199 .9 \\
(1.93 \text { to } 3.30)^{d}\end{array}$ & $\begin{array}{c}2.31 \\
(1.74 \text { to } 2.88)^{d}\end{array}$ \\
\hline
\end{tabular}

$B=$ The adjusted mean difference. ${ }^{a}$ Shows the mean difference in blood pressure for patients from a given ethnic group compared to white British patients. Coefficients are adjusted for age, sex, number of comorbidities, and social deprivation. ${ }^{b}$ Caribbean and African categories combined. ${ }^{c} P<0.05 .{ }^{d} P<0.001$. 
illnesses was higher, with $19.4 \%$ of black patients in the sample having any one of the chronic conditions that were looked at, compared to $13 \%$ of the white British group.

As well as looking at QOF target outcomes, differences in absolute blood pressure levels between ethnic groups were also examined (Table 5). Again this showed black patients achieving poorer blood pressure control, with a mean systolic blood pressure that was $2.96 \mathrm{mmHg}(95 \% \mathrm{Cl}=2.17$ to 3.75) greater than that of white patients. This also revealed significantly lower blood pressure levels for Asian patients, who had a mean systolic blood pressure that was $1.42 \mathrm{mmHg}(95 \% \mathrm{Cl}=2.70$ to $0.14)$ less than that of white patients.

Looking at the ethnic subgroups, the results show a tendency for African patients to have poorer blood pressure control. For example, the odds of African patients with diabetes meeting QOF targets for blood pressure control were significantly reduced (OR 0.6; $95 \% \mathrm{Cl}=0.50$ to 0.79 ) compared to white patients, whereas for Caribbean patients there was no significant difference. One exception was patients with CHD where, in this case, it was Caribbean patients who showed significantly poorer blood pressure control (OR 0.53; $95 \% \mathrm{Cl}=0.37$ to 0.77 ), while Africans failed to show a significant difference.

This may reflect the higher prevalence of CHD in the Caribbean sample, which was almost twice that of the African sample. When the model was re-run, directly comparing blood pressure control for Africans and Caribbeans, the above differences failed to reach statistical significance. An exception was for patients with diabetes, where African patients showed significantly decreased odds of meeting the QOF blood pressure target compared to Caribbean patients (OR 0.76; $95 \% \mathrm{Cl}=0.59$ to 0.97 ), although this only just reached statistical significance $(P=0.028)$.

\section{DISCUSSION}

\section{Summary of main findings}

The study found that overall blood pressure monitoring was at least as good for BEM patients with chronic conditions as for the majority white population. However, black patients were consistently less likely to have their blood pressure adequately controlled.

Therefore, despite evidence that inequality in blood pressure control according to social deprivation has steadily narrowed over the past few years, there has not been a corresponding reduction in ethnic health inequality.

\section{Strengths and limitations of the study}

This study benefited from a large sample of patient records covering a range of ethnic groups and chronic conditions. The dataset was particularly suited to this study as Lambeth is an area of contrasting social deprivation with a large BEM population. While this provided enough statistical power to compare the main ethnic groups, it proved to be underpowered for the ethnic subgroup analysis. Also, the data were cross-sectional and, given that Lambeth has a highly mobile population, it is possible that this has affected overall treatment outcomes. For example, some BEM patients may have just begun treatment, after recently moving into the practice area and, therefore, their blood pressure levels may be higher. It was, however, possible to adjust the model to take into account the number of years registered, and this did not make any appreciable difference to the results.

The study was based on data collected as part of the QOF, the limitations of which have been well documented elsewhere. ${ }^{22,23}$ One possible source of bias in data based on QOF returns is the use of exception reporting to exclude patients. ${ }^{14,15}$ However, it was possible to overcome this in the present study by accessing data for all patients. As routine administrative data were used, the recorded diagnoses were not independently verified and there might be systematic bias in recording comorbidities. Lifestyle factors are another area where QOF data are relatively limited, and it was not possible to account for differences in exercise, diet, or obesity, all of which may be relevant confounders. It is worth noting that when the effect of smoking was examined, it was found that this made little difference to the results; hence this was excluded from the analysis.

\section{Comparison with existing literature}

The encouraging results for blood pressure monitoring for BEM patients are comparable with those of previous studies., ${ }^{8,11}$ Cappuccio et al found that black people with hypertension were more likely to be detected, although less well managed, than white people. ${ }^{8}$ It has been argued that blood pressure monitoring rates are relatively good for BEM patients, due to a greater awareness among GPs of ethnic differences in hypertension. ${ }^{10}$ Another factor may simply be that monitoring can be more easily conducted on an opportunistic basis, while achieving adequate blood pressure control itself demands sustained therapeutic effort and patient engagement, posing a greater clinical management challenge. ${ }^{24}$

The study results also confirm those of previous studies reporting poorer blood pressure control for black people with chronic conditions. ${ }^{8,16,25}$ It is notable that those studies that have so far failed to show any ethnic difference were based on smaller samples of 
BEM patients, because either they relied on national survey data, ${ }^{11,13}$ or they were concentrated in a small locality. ${ }^{12}$ For example, Nazroo et al looked at patients treated for hypertension in four waves (1998-2004) of the Health Survey for England, and detected only minimal ethnic differences in blood pressure control. ${ }^{11}$ Despite being confined to one local authority area, the present study benefited from a larger sample of BEM patients, and therefore had potentially greater power to detect a difference.

It is notable that the results showing a significant ethnic difference remain well within the 95\% confidence intervals of those reported in the latter study. A further factor may be that the present study, by concentrating on one large urban area, is well placed to represent the experience of BEM patients, given that the majority of the BEM population is concentrated in a few urban areas in the UK. Despite some effort to represent more concentrated BEM populations, much of the Health Survey for England sample covers BEM participants in areas that are predominantly white..$^{26}$ It is possible, therefore, that ethnic differences in treatment may be much less distinct in these areas, explaining the overall lack of difference reported by studies using these data. ${ }^{11,13,27}$ Conversely, the present results are very similar to those reported in a similar study in south west London. ${ }^{16}$ Using data collected up to the beginning of 2006, the latter study looked at records for GP patients with hypertension soon after QOF was introduced. That the present findings are so similar suggests that there has been little subsequent reduction in ethnic health inequalities.

The results of the present study also suggest that African individuals may have poorer blood pressure control compared to Caribbean people. However, there is very little previous research in this area to compare this with. While the present study looks at those with chronic diseases, only two previous studies have compared blood pressure for African and Caribbean patients overall, and both failed to show any significant difference, although both studies were based on much smaller samples. ${ }^{6,8}$ There has, though, been some interesting recent research that points to important differences in cerebrovascular risk between these two ethnic groups. ${ }^{28}$

\section{Implications for future research and clinical practice}

Poor blood pressure control has important implications for cardiovascular disease risk and, it has been argued that because hypertension is largely treatable, even small ethnic differences can have major implications for health resources. ${ }^{29}$ It has been established that lowering blood pressure levels results in a proportional decrease in cardiovascular disease risk, with a reduction of $5 \mathrm{mmHg}$ diastolic blood pressure corresponding to a $34 \%$ reduction in the risk of stroke and a $21 \%$ reduction in the risk of ischaemic heart disease..$^{30}$ On this basis, the present findings translate into a substantial additional cardiovascular disease risk for black patients with hypertension. The study was not confined to patients with hypertension but looked also at those with other chronic diseases for which poor blood pressure control increases overall cardiovascular disease risk. Of particular concern are stroke patients, where the mortality risk is much higher in the black population. ${ }^{1}$ While the present results for stroke patients did not achieve statistical significance they are consistent with the overall pattern of poorer blood pressure control in black patients. The study also looked at different ethnic subgroups, and further study is now needed to see if the results are replicated in other African-Caribbean communities.

While this study was able to show some clear ethnic differences in achievement of blood pressure targets, the mechanism behind this can only be speculated at this stage. It is possible that medication adherence, differentiated by ethnic group, may partly explain these differences, as some US studies have demonstrated, ${ }^{31,32}$ although further research is needed to establish this. Another question is whether black patients are being prescribed lower volumes of drugs to treat hypertension. More fundamentally, poorer blood pressure control in black patients with hypertension and other chronic diseases related to cardiovascular disease, may reflect higher population norms for mean blood pressure values in the black population. ${ }^{7}$ In consequence, this could mean that greater blood pressure reductions are required for this group to achieve fixed blood pressure targets. Another factor may be whether or not GPs adhere to ethnic-specific treatment guidelines for blood pressure management, ${ }^{33}$ and further work is needed to explore the different classes of medication prescribed and how these might contribute to ethnic differences in blood pressure outcomes. The authors are, therefore, currently working on a follow-on study looking specifically at the relationship between blood pressure control and the class of blood pressure drugs prescribed.

\section{Funding body}

The study was supported by a grant from the Guy's and St. Thomas' Charity.

\section{Ethical approval}

Ethical approval was given by the South East Research Ethics Committee - 07MRE01/26

Competing interests

The authors have stated that there are none

Acknowledgements

We would like to acknowledge the contribution of the 
Lambeth patients and practices who allowed us access to their data.

\section{Discuss this article}

Contribute and read comments about this article on the Discussion Forum: http://www.rcgp.org.uk/bjgp-discuss

\section{REFERENCES}

1. Lip GYH, Barnett AH, Bradbury A, et al. Ethnicity and cardiovascular disease prevention in the United Kingdom: a practical approach to management. J Hum Hypertens 2007; 21(3): $183-211$.

2. Stewart JA, Dundas R, Howard RS, et al. Ethnic differences in incidence of stroke: prospective study with stroke register. $B M$ J 1999; 318(7189): 967-971.

3. Smith GD, Hart C, Watt G, et al. Individual social class, area-based deprivation, cardiovascular disease risk factors, and mortality: the Renfrew and Paisley Study. J Epidemiol Community Health 1998; 52(6): 399-405.

4. Smith GD, Bartley M, Blane D. The Black report on socioeconomic inequalities in health 10 years on. BMJ 1990; 301(6748): 373-377.

5. Ezzati M, Lopez AD, Rodgers A, et al. Selected major risk factors and global and regional burden of disease. Lancet 2002; 360(9343): 1347-1360.

6. Chaturvedi N, McKeigue PM, Marmot MG. Resting and ambulatory blood pressure differences in Afro-Caribbeans and Europeans. Hypertension 1993; 22(1): 90-96.

7. Lane D, Beevers DG, Lip GYH. Ethnic differences in blood pressure and the prevalence of hypertension in England. J Hum Hypertens 2002; 16(4): 267-273.

8. Cappuccio FP, Cook DG, Atkinson RW, Strazzullo P. Prevalence, detection, and management of cardiovascular risk factors in different ethnic groups in south London. Heart 1997; 78(6): 555-563.

9. Agyemang C, Bhopal RS. Is the blood pressure of South Asian adults in the UK higher or lower than that in European white adults? A review of cross-sectional data. J Hum Hypertens 2002. 16(11): 739-751.

10. Cappuccio FP. Ethnicity and cardiovascular risk: variations in people of African ancestry and South Asian origin. J Hum Hypertens 1997; 11(9): 571-576.

11. Nazroo JY, Falaschetti E, Pierce M, Primatesta P. Ethnic inequalities in access to and outcomes of healthcare: analysis of the Health Survey for England. J Epidemiol Community Health 2009; 63(12): 1022-1027.

12. Cruickshank JK, Bannan LT, Beevers M, et al. Blood pressure in black, white and Asian factory workers in Birmingham. Postgrad Med J 1983; 59(696): 622-626.

13. Primatesta P, Bost L, Poulter NR. Blood pressure levels and hypertension status among ethnic groups in England. J Hum Hypertens 2000; 14(2): 143-148.

14. Doran T, Fullwood C, Kontopantelis E, Reeves D. Effect of financial incentives on inequalities in the delivery of primary clinical care in England: analysis of clinical activity indicators for the quality and outcomes framework. Lancet 2008; 372(9640): 728-736.

15. Ashworth M, Medina J, Morgan M. Effect of social deprivation on blood pressure monitoring and control in England: a survey of data from the quality and outcomes framework. BMJ 2008; 337 : a2030.

16. Millett C, Gray J, Bottle A, Majeed A. Ethnic disparities in blood pressure management in patients with hypertension after the introduction of pay for performance. Ann Fam Med 2008; 6(6): 490-496.
17. Office for National Statistics. Census 2001. http://www.neighbourhood.statistics.gov.uk/dissemination/ (accessed 10 Mar 2011)

18. Kumarapeli P, Stepaniuk R, de Lusignan S, et al. Ethnicity recording in general practice computer systems.J Public Health (Oxf) 2006; 28(3): 283-287.

19. Pinto R, Ashworth M, Seed P, et al. Differences in the primary care management of patients with psychosis from two ethnic groups: a population-based cross-sectional study. Fam Pract 2010; 27(4): 439-446.

20. Domanski MJ, Mitchell GF, Norman JE, et al. Independent prognostic information provided by sphygmomanometrically determined pulse pressure and mean arterial pressure in patient with left ventricular dysfunction. J Am Coll Cardiol 1999; 33(4): 951-958.

21. Department of Communities and Local Government. Indices of deprivation 2007.

http://webarchive.nationalarchives.gov.uk/+/http://www.communit ies.gov.uk/communities/neighbourhoodrenewal/deprivation/depri vation07/ (accessed 28 Aug 2010).

22. Mangin D, Toop L. The quality and outcomes framework: what have you done to yourselves? Br J Gen Pract 2007; 57(539): 435-437.

23. Campbell SA, McDonald R, Lester $\mathrm{H}$. The experience of pay for performance in english family practice: a qualitative study. Ann Fam Med 2008; 6(3): 228-234.

24. McLean G, Sutton M, Guthrie B. Deprivation and quality of primary care services: evidence for persistence of the inverse care law from the UK Quality and Outcomes Framework. J Epidemiol Community Health 2006; 60(11): 917-922.

25. Gray J, Millett C, Saxena S, et al. Ethnicity and quality of diabetes care in a health system with universal coverage: population-based cross-sectional survey in primary care. J Gen Intern Med 2007; 22(9): 1317-1320.

26. Erens B, Primatesta P, Prior G. Health Survey for England 1999: the health of minority ethnic groups. London: The Stationery Office, 2001.

http://www.dh.gov.uk/en/Publicationsandstatistics/Publications/Pu blicationsStatistics/DH_4009393 (accessed 3 Mar 2011).

27. Abbotts J, Harding S, Cruickshank K. Cardiovascular risk profiles in UK-born Caribbeans and Irish living in England and Wales. Atherosclerosis 2004; 175(2): 295-303.

28. Smeeton NC, Heuschmann PU, Rudd AG, et al. Incidence of hemorrhagic stroke in black Caribbean, black African, and white populations: the South London stroke register, 1995-2004. Stroke 2007; 38(12): 3133-3138.

29. Brown MJ. Hypertension and ethnic group. BMJ 2006; 332(7545): 833-836.

30. Law M, Wald N, Morris J. Lowering blood pressure to prevent myocardial infarction and stroke: a new preventive strategy. Health Technol Assess 2003; 7(31): 1-94.

31. Dickson M, Plauschinat CA. Racial differences in medication compliance and healthcare utilization among hypertensive Medicaid recipients: fixed-dose vs free-combination treatment. Ethn Dis 2008; 18(2): 204-209.

32. Taira DA, Wong KS, Frech-Tamas F, Chung RS. Copayment level and compliance with antihypertensive medication: analysis and policy implications for managed care. Am J Manag Care 2006; 12(11): 678-683.

33. National Institute for Health and Clinical Excellence. Hypertension: management of hypertension in adults in primary care. NICE clinical guideline 34. London: National Institute for Health and Clinical Excellence, 2006.

http://guidance.nice.org.uk/nicemedia/live/10986/30113/30113.pdf (accessed 3 Mar 2011). 